\title{
DETERMINATION OF THERMAL DIFFUSIVITIES, THERMAL CONDUCTIVITIES, AND SOUND SPEEDS OF ROOM TEMPERATURE IONIC LIQUIDS BY THE TRANSIENT GRATING TECHNIQUE
}

\author{
Clifford Frez ${ }^{*}$ and Gerald J. Diebold \\ Department of Chemistry, Brown University, \\ 324 Brook Street, Providence, Rhode Island 02906 \\ and \\ Chieu D. Tran and Shaofang Yu \\ Department of Chemistry, Marquette University \\ P. O. Box 1881, Milwaukee, Wisconsin 53201
}

Supporting Information

* To whom correspondence may be addressed. Tel: 401-863-3619. Email:frez@ brown.edu. 


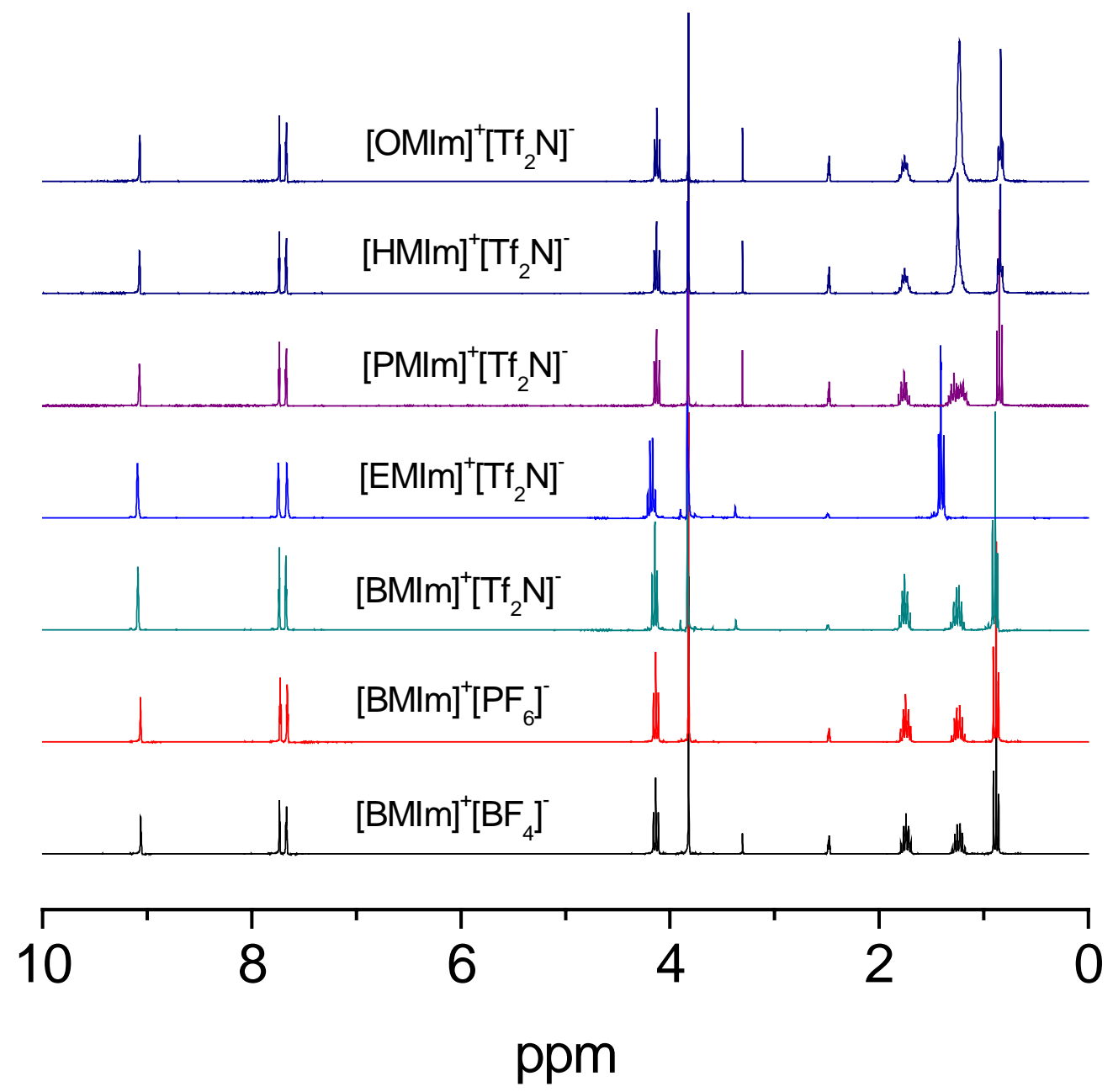

Figure S1. ${ }^{1} \mathrm{H}$ NMR spectra of seven ionic liquids ([BMIm $]^{+}\left[\mathrm{BF}_{4}\right]^{-}$, $[\mathrm{BMIm}]^{+}\left[\mathrm{PF}_{6}\right]^{-}$, $[\mathrm{BMIm}]^{+}\left[\mathrm{Tf}_{2} \mathrm{~N}\right]^{-},[\mathrm{EMIm}]^{+}\left[\mathrm{Tf}_{2} \mathrm{~N}\right]^{-},\left[\mathrm{PMIm}^{+}\left[\mathrm{Tf}_{2} \mathrm{~N}\right]^{-},\left[\mathrm{HMIm}^{+}\left[\mathrm{Tf}_{2} \mathrm{~N}\right]^{-}\right.\right.$, and $[\mathrm{OMIm}]^{+}\left[\mathrm{Tf}_{2} \mathrm{~N}\right]^{-}$used in this work (in DMSO-d6). 